\title{
REGISTRY OF PATIENTS WITH PULMONARY HYPERTENSION PRESENTED TO AIN-SHAMS UNIVERSITY HOSPITALS
}

\author{
Abdelrahman Elsayed, Dina Adel Ezzeldin, Hebatallah Mohamed Attia and \\ Maiy Hamdy Elsayed.
}

Department of Cardiology, Faculty of Medicine, Ain Shams University, Cairo, Egypt.

.Corresponding author:

Abdelrahman Elsayed Attia Mobile: 01007155165

E mail:

drabdoelsayed@yahoo.com,

Received: 7/5/2019

Accepted: 4/6/2019

\begin{abstract}
Background: Registries of patients with P.HTN have been instrumental in characterizing the history of the disease.

Aim of the work: to establish a registry of patients with pulmonary hypertension presented to our hospital

Patients and Methods: cross-sectional study involving 150 patients with pulmonary hypertension from November 2017 to May 2019.

\section{Results:}

1- Pediatric group: 105 patients, 55 males and 50 females, the mean age was 5 years, $17.1 \%$ had Down syndrome. The most common etiology was VSD

The most common presentation was dyspnea, the mean MPAP was 42 , the mean LVEDP was 11 , the mean PVR was 4.73 and the mean RAP was 8.79.

The mean RVSP was 64.48, the mean MPAP by echo was 46.45 .

58 patients was compliant to regular follow up at our unit, 47 patients missed their follow up.

2- Adult age group: 45 patients, 15 males and 30 females andt he mean age was 37 years, $17.8 \%$ had delay in receiving treatment, the most common etiology was ASD and The most common presentation was dyspnea.

The mean MPAP was 41.63, the mean LVEDP was 12.42 , the mean PVR was 4.63 and the mean RAP was 7.81 and the mean RVSP was 70.38 , the mean MPAP by echo was 47.11 .33 patients $(78.6 \%)$ was compliant to regular follow up at our unit, 9 patients missed their follow up

Conclusion: Our study confirmed many similarities between our patients, and international data, Patients with pulmonary hypertension should be followed in well-established clinics with a proper protocol.
\end{abstract}

Key words: registry, pediatric pulmonary hypertension, catheterization, congenital heart diseases.

\section{INTRODUCTION:}

Registries of patients with pulmonary arterial hypertension have been instrumental in characterizing the presentation and history of the disease providing a basis for prognostication. Since initial accumulation of data conducted in the 1980s, subsequent databases have yielded information about the demographic factors, treatment, and survival and comparisons between populations in different eras and environments ${ }^{(1)}$ 
The epidemiology of pulmonary hypertension and its burden has not been studied yet in Egypt

\section{AIM OF THE WORK:}

To establish a registry for patients with pulmonary hypertension including their clinical data, echocardiographic evaluation, any intervention and the clinical outcome for patients presented to congenital and structural heart disease unit at Ain shams university hospitals.

\section{PATIENTS AND METHODS:}

The study was conducted in the period from November 2017 to May 2019 including patients diagnosed with pulmonary arterial hypertension.

All patients after written informed consent approved by the ethical committee have been included into our registry and subjected to the following:

1) History taking including: Age, paediatric age group (0-18yrs), adult age group ( $>18 \mathrm{yrs})$, age at diagnosis, age of starting the treatment, postnatal events, the presenting symptom and previous cardiac catheterization or surgical intervention.

2) Physical examination: Including: General examination and local cardiac examination

Echocardiography including: This was done for all patients with ECG gating machine, mostly with the patients lying in the left lateral decubitus position, using a General Electric (GE) Vingmed Ultrasound Vivid 5 or Vivid 9 system with the suitable probe for the patient with a suitable frequency. The examination was done for all patients in standard precordial apical $(2,3-$ and 4-chamber views), parasternal (longand short- axis views) and subcostal views. RV function was assessed from the apical 4chambre view using the conventional parameters: fractional area change (FAC) and tricuspid annular plane systolic excursion (TAPSE), RVSP, PA Diastolic Pressure (PADP), Mean PA Pressure (MPAP), The Right atrial pressure (RAP) Exercise capacity assessment by 6MWT: The test was performed along a long, flat, straight, enclosed corridor with a hard surface. We used 30 meters walking corridor with marks on the wall every 3 meters. The patient had to turn around at the end of each 30 meters to complete 1 lap at 60 meters.

\section{Cardiac catheterization and angio- $\operatorname{graphy}^{(2)}$ :}

- It was performed under $100 \%$ oxygen supplementation

- It was done through femoral vein, Side hole catheters were used as multipurpose catheters and under biplane fluoroscopic guidance of Antero-Posterior and lateral views

- Mean right atrial pressure, mean pulmonary artery pressure and LV end diastolic pressure was measured.

PVR was calculated by the following equations: $\mathrm{PVR}=\mathrm{MPAP}-\mathrm{LVEDP} / \mathrm{QP}$

Management: including medical, surgical or catheter-based treatment.

\section{Medical treatment either mono- therapy or combination therapy, compliance}

Follow up including: patients improved or deteriorated, compliance, Need for new catheterization or surgery, ICU admission, Syncope, Clinical signs of heart failure, RV functions and pericardial effusionj

\section{RESULTS:}

This registry included 150 patients who were sub-divided into two groups, P.HTN in pediatric age group (0-18yrs) and P.HTN in adult age group ( $>18 y$ rs). 


\section{1- peditaric age group:}

The pediatric age group included 105 patients, 55 males (52.4\%) and 50 females (47.6\%)

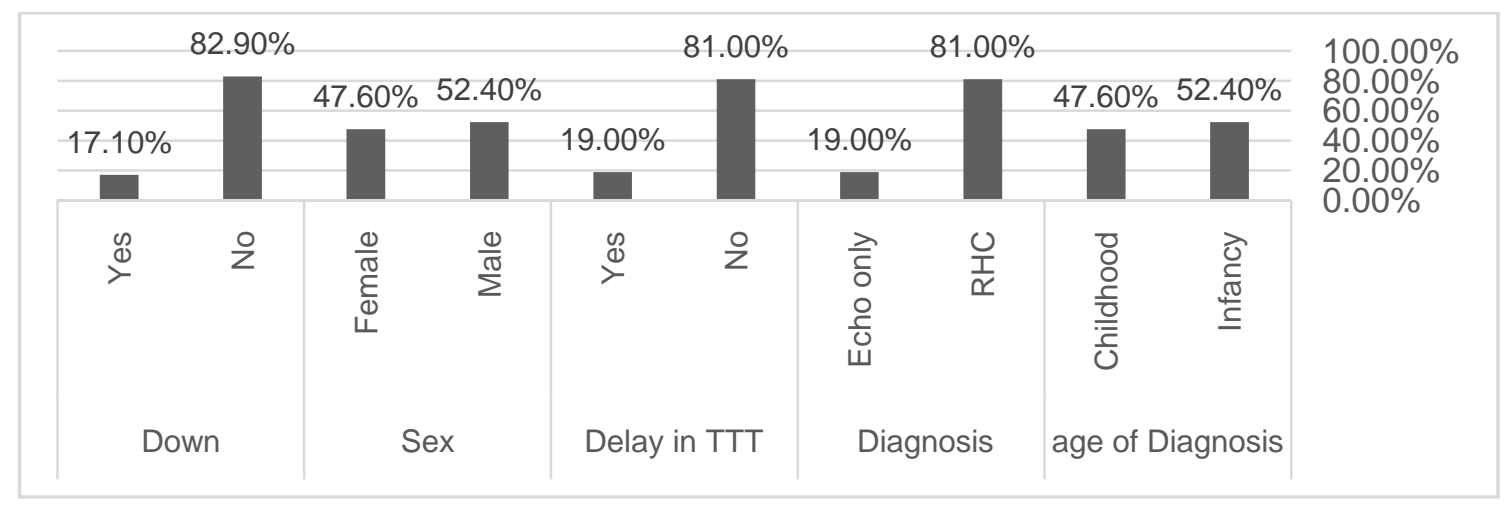

The etiology:

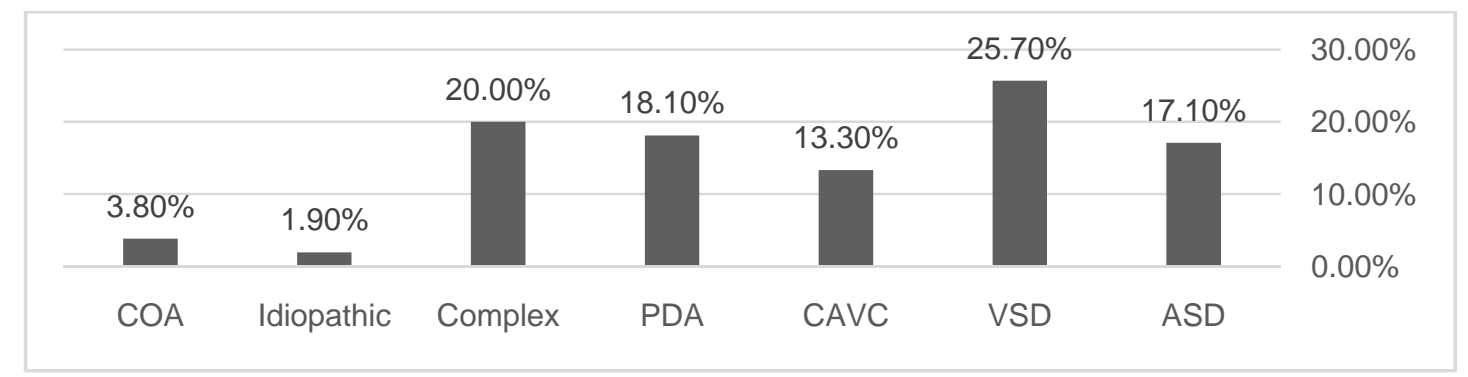

\section{The presenting symptom:}

51 patients $(48.6 \%)$ presented by failure to thrive, 22 patients $(21 \%)$ were discovered accidentally, one patient presented by cyanosis, 53 patients $(50.5 \%)$ presented by dyspnea, 2 patients $(1.9 \%)$ presented by chest pain, 6 patients $(5.7 \%)$ presented by syncope and 6 patients $(5.7 \%)$ presented by palpitations

\section{Catheterization data:}

\begin{tabular}{|c|c|c|}
\hline \multirow{2}{*}{} & \multicolumn{2}{|c|}{ Pediatric } \\
\cline { 2 - 3 } & Mean \pm SD & Range \\
\hline SBP & $96.86 \pm 14.1$ & $70-150$ \\
\hline DBP & $64.62 \pm 8.93$ & $50-95$ \\
\hline SAT & $93.2 \pm 10.1$ & $0-99$ \\
\hline MPAP & $42.43 \pm 14.15$ & $25-70$ \\
\hline LVEDP & $11.74 \pm 3.17$ & $5-20$ \\
\hline PVR & $4.73 \pm 3.17$ & $1-14$ \\
\hline RAP & $8.79 \pm 3.34$ & $5-16$ \\
\hline
\end{tabular}

\section{Echocardiography data:}

The mean RVSP was $64.48 \mathrm{mmHg} \pm$ 19.4 (Range $30-130$ ), the mean MPAP by echo was $46.45 \mathrm{mmHg} \pm 14.96$ (Range 2090), the mean RAP by echo was $7.76 \mathrm{mmHg}$ \pm 3.73 (Range $0-15$ ), the mean EF was $61.99 \pm 8.84$ (Range $0-78$ ).69 patients (65.7\%) had dilated RV dimensions, 23 patients $(21.9 \%)$ had impaired RV functions by TAPSE. 20 patients $(19 \%)$ had impaired RV functions by FAC, 54 patients $(51.4 \%)$ had dilated LV dimensions. 


\section{Medical treatment:}

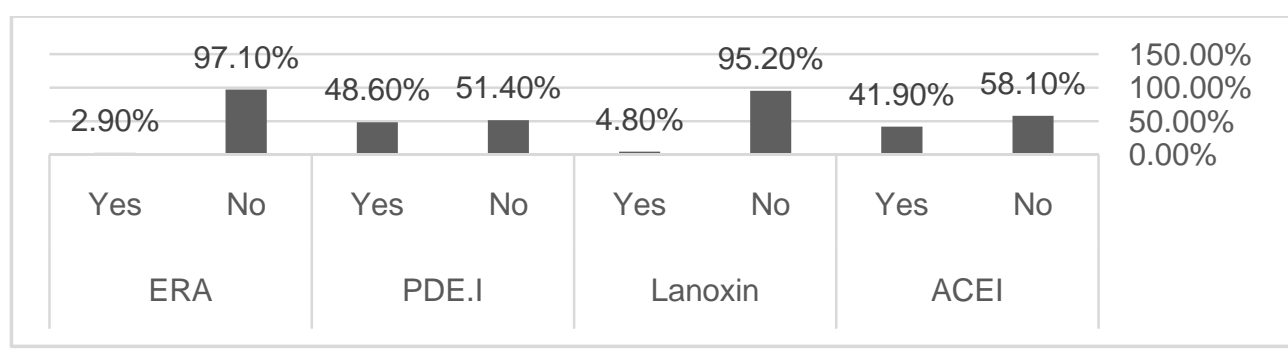

Intervention: 9 patients $\quad(9.8 \%)$ underwent ASD device closure, 7 patients (7.6\%) underwent percutaneous PDA, 62 patients $(67.4 \%)$ underwent hemodynamic study, 9 patients $(9.8 \%)$ underwent PDA surgical closure, 2 patients $(2.2 \%)$ underwent balloon aortic valvuloplasty and 3 patients (3.3\%) underwent balloon COA dilatation

Complications after catheterization: 14 patients had hematoma, 5 patients had lost peripheral pulsations that required heparin infusion

51 patients were referred for surgery, 16 patients were prescribed ERA, 1 patient waiting for MAPCAS closure, 1 patient planned to have AV fistula closure

The etiology:
Follow up: 58 patients $(55.2 \%)$ was compliant to regular follow up at our unit, 47 patients (44.8\%) missed their follow up, 3 patients died

\section{2-Adult age group:}

The adult age group included 45 patients, 15 males $(33.3 \%)$ and 30 females $(66.7 \%)$. The mean age of the group was 37.78 years \pm 11.45 (range 19-64 years), 8 patients $(17.8 \%)$ had delay in receiving the treatment 43 patients $(95.6 \%)$ were diagnosed by right heart catheterization and 2 patients $(4.4 \%)$ were diagnosed by echo only.

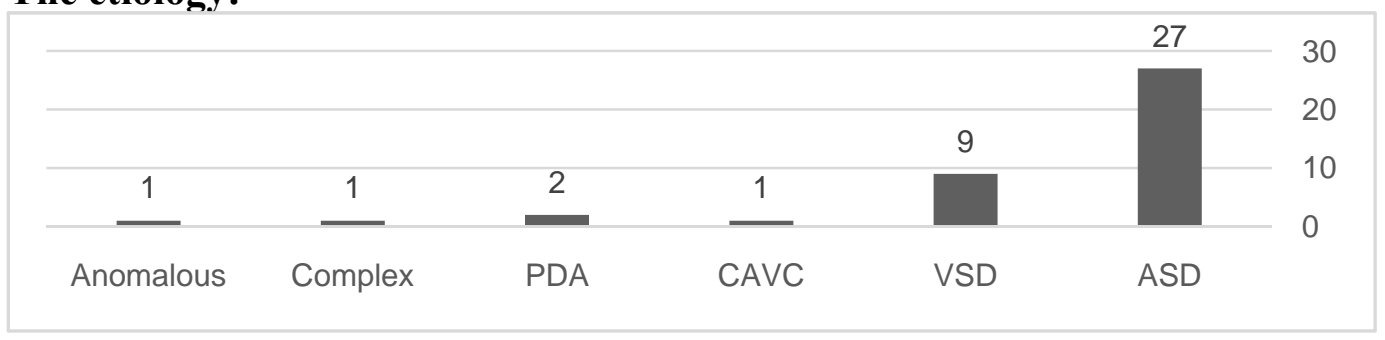

\section{The presenting symptom:}

No patients were presented by failure to thrive or discovered accidentally, two patients presented by cyanosis, 40 patients (88.9\%) presented by dyspnea, 14 patients (31.1\%) presented by chest pain, 12 patients $(26.7 \%)$ presented by syncope and 17 patients $(37.7 \%)$ presented by palpitations
Catheterization data:

\begin{tabular}{|c|c|c|}
\hline \multirow{2}{*}{} & \multicolumn{2}{|c|}{ Adult } \\
\cline { 2 - 3 } & Mean \pm SD & Range \\
\hline SBP & $124.44 \pm 19.95$ & $90-190$ \\
\hline DBP & $76.33 \pm 9.56$ & $60-100$ \\
\hline SAT & $94.87 \pm 3.56$ & $85-99$ \\
\hline MPAP & $41.63 \pm 12.89$ & $27-70$ \\
\hline LVEDP & $12.42 \pm 2.9$ & $8-20$ \\
\hline PVR & $4.63 \pm 3.68$ & $1.6-17$ \\
\hline RAP & $7.81 \pm 3.74$ & $5-15$ \\
\hline
\end{tabular}


Echocardiography data: The mean RVSP was $70.38 \mathrm{mmHg} \pm 20.86$ (Range 35 - 120), the mean MPAP by echo was 47.11 $\mathrm{mmHg} \pm 12.43$ (Range 26-70), the mean RAP by echo was $7.78 \mathrm{mmHg} \pm 4.2$ (Range 5 - 15), the mean EF was $62.98 \pm 4.41$
(Range $50-70) .40$ patients $(88.9 \%)$ had dilated RV dimensions, 9 patients $(20 \%)$ had impaired RV functions by TAPSE and FAC.9 patients $(20 \%)$ had dilated LV dimensions.

\section{Medical treatment:}

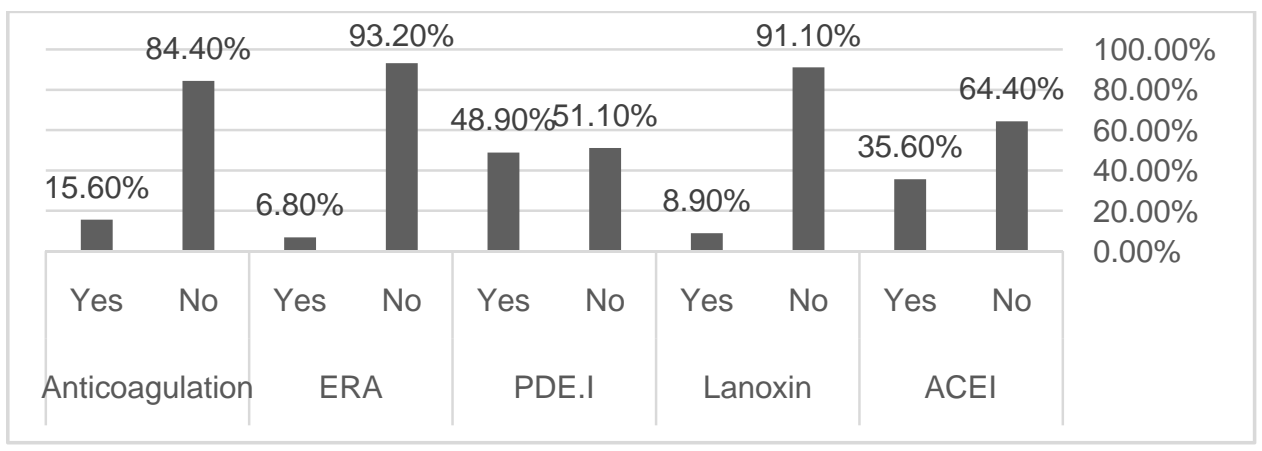

Intervention: 16 patients (37.2\%) underwent ASD device closure, 1 patient (2.3\%) underwent percutaneous PDA closure, 23 patients $(53.5 \%)$ underwent hemodynamic study, 2 patients $(4.7 \%)$ underwent PDA surgical closure, 1 patient $(2.3 \%)$ underwent surgical COA repair

2 patients were referred for surgery, 16 patients were prescribed ERA, 1 patient underwent PCI to RCA, 1 patient planned to have balloon angioplasty to peripheral pulmonary tree (CTEPH)

The mean MPA diameter was 24.84 $\mathrm{mm} \pm 4.24$ (range 18-35), the mean 6MWT on presentation was 312.93 meters \pm 81.92 range (120-430), the mean 6MWT on FUP was 351.5 meters \pm 113.58 (range (100-500)

Follow up: 33 patients $(78.6 \%)$ was compliant to regular follow up at our unit, 9 patients $(21.4 \%)$ missed their follow up, 4 patients died

\section{Patients with Down syndrome:}

They were 18 patients, the major presenting symptom was failure to thrive in 11 patients $(61.1 \%)$
The most common congenital heart disease was CAVC in 8 patients $(44.4 \%)$ followed by VSD in 6 patients $(33.3 \%)$

6 patients $(33.3 \%)$ developed hematoma after cath, one patient had lost P.P that needed heparin infusion

\section{Adult patients with Eisenmenger} syndrome:

They were 12 patients, the major presenting symptom was syncope in 8 patients $(66.7 \%)$ followed by chest pain in 7 patients $(58.3 \%)$.

The most common congenital heart disease was VSD in 6 patients $(50 \%)$ followed by ASD in 4 patients $(33.3 \%)$

8 patients $(66.7 \%)$ had impaired RV functions by TAPSE and FAC

The mean 6MWT was 218.75 meters \pm 65.58 (range 120-340)

\section{DISCUSSION:}

The Tracking Outcomes and Practice in Pediatric Pulmonary Hypertension (TOPP) registry was a prospective registry that provides information on demographics, 
diagnostic evaluation, treatment and outcomes in pediatric pulmonary hypertension. It identified important clinical features specific to the care of pediatric pulmonary hypertension, which drew attention to the need for pediatric data rather than extrapolation from adult studies ${ }^{(3)}$. So, in Ain Shams registry, our primary focus was the pediatric age population composing $70 \%$ for our study population.

Also, pulmonary hypertension due to congenital heart disease composed a small percentage of all previous registries so our focus also was on this population composing $95 \%$ of our study population

Basic characteristics: In pediatric group, we studied 105 patients, the mean age was 5years, $52.4 \%$ were males and $47.6 \%$ were females, $17 \%$ of them had Down syndrome

The mean age was higher than Netherlands registry ${ }^{(4)}$ in which they studied 3263 , the mean age was 2.2 years, with 80 females $(51 \%)$, This could be explained by their inclusion of patients with transient pulmonary hypertension

Down syndrome constituted $18 \%$ of the patients, which is similar to our registry

It was different also form the TOPP registry ${ }^{(5)}$ where they studied 362 patients, the mean age was 7.5 years, $59 \%$ females, Down syndrome constituted $13 \%$ of the patients, which is lower than our registry

In adult age group we studied 45 patients, the mean age was 37 years, $33.3 \%$ were males and $66.7 \%$ were females

This was similar to the REHAP registry (6) , they studied 240 adult patients, the mean age was 37 years, and $67.9 \%$ were females.

\section{Method of diagnosis:}

$85 \%$ of our patient was diagnosed by heart catheterization and $15 \%$ was diagnosed by echocardiography
This was similar to all the large registries as it is the gold standard for diagnosis of pulmonary hypertension as recommended by guidelines.

This was different from Pan African Pulmonary hypertension Cohort (PAPUCO) study, which $\mathrm{PH}$ was decided to be diagnosed by specialist cardiologists using echocardiography (right ventricular systolic pressure $>35 \mathrm{~mm} \mathrm{Hg}$, absence of pulmonary stenosis and acute right heart failure), usually accompanied by symptoms and signs suggestive of pulmonary hypertension, right heart catheterization was decided be performed at the discretion of the treating physician, this could be justified easily by the lack of resources ${ }^{(7)}$.

\section{The underlying etiology:}

$95 \%$ of our patients had pulmonary hypertension due to congenital heart diseases, the most common underlying etiology in pediatric age group was VSD followed by complex congenital heart disease

The most common underlying etiology in adult age group was ASD followed by VSD

This was different from the Netherlands registry in which the complex congenital heart diseases were the commonest followed by $\operatorname{VSD}^{(4)}$.

The percentage of patients with PHTN-CHD in our study was higher than other registries, this could be justified by the specific nature of our unit which is specialized in congenital heart diseases

\section{The presenting symptom:}

The most common presenting symptom in pediatric age group was dyspnea followed by failure to thrive and The most common presenting symptom in adult age group was dyspnea followed syncope and chest pain. 
This was consistent with most of the registries regarding dyspnea being the most common symptom

\section{Catheterization data:}

The mean MPAP was $41 \mathrm{mmHg}$, the mean LVEDP was $12 \mathrm{mmHg}$, the mean PVR was 4.63 and the mean RAP was 7.81 .

Our catheterization data was similar to the Netherlands registry ${ }^{(4)}$, as they studied the same parameters as us, the mean MPAP was $49 \mathrm{mmHg}$, the mean PCWP was 9 $\mathrm{mmHg}$ and the mean RAP was $7 \mathrm{mmHg}$.

It was also similar to the REVEAL registry ${ }^{(8)}$, the mean MPAP was $59 \mathrm{mmHg}$, the mean PCWP was $9 \mathrm{mmHg}$ and the mean RAP was $7 \mathrm{mmHg}$.

In the REHAP registry ${ }^{(6)}$, the mean MPAP was $62 \mathrm{mmHg}$ and the mean RAP was $7 \mathrm{mmHg}$.

In the TOPP registry ${ }^{(5)}$, the mean MPAP was $61 \mathrm{mmHg}$, the mean PCWP was 9 $\mathrm{mmHg}$ and the mean RAP was $7 \mathrm{mmHg}$.

A major difference between our registry and other registries that is LVEDP was measured directly instead of PCWP as the measurement of PCWP may be highly variable and depend on the volume status of the patient.

\section{Echocardiography data:}

The mean RVSP was $70 \mathrm{mmHg}$, the mean MPAP by echo was $47 \mathrm{mmHg}$, the mean RAP by echo was $7 \mathrm{mmHg}$, and the mean MPA diameter was $24 \mathrm{~mm}$

This was similar to the Netherlands registry ${ }^{(4)}$, as they studied only RVSP and MPAP, the mean MPAP was $41 \mathrm{mmHg}$ and the mean RVSP was $51 \mathrm{mmHg}$.

This was similar also to the Pan African Pulmonary hypertension Cohort (PAPUCO) study in which the mean RVSP was $58 \mathrm{mmHg}^{(7)}$.
In our study we used TAPSE and FAC as the echocardiography parameters to assess RV systolic functions

In pediatric age group, $21.9 \%$ had impaired RV functions by TAPSE, $19 \%$ had impaired RV functions by FAC

In adult age group, $20 \%$ had impaired RV functions by TAPSE and FAC.

Among adult age group, patients who had Impaired RV functions by TAPSE and FAC had significantly higher MPAP (mean $60 \pm 6.55)$ with $\mathrm{P}$ value $<0.001$.

Among adult age group, patients who had Impaired RV functions by TAPSE and FAC had significantly lower 6MWT (mean 208.89 meters \pm 62.34) with $\mathrm{P}$ value $<0.001$.

A large meta-analysis was carried by Lee et al. and the conclusion was that FAC provides a more accurate estimate of $\mathrm{RV}$ systolic function (RVSF) compared with TAPSE. Adoption of FAC as a routine tool for the assessment of RVSF should be considered, especially since it is also an independent predictor of morbidity and mortality. Further studies will be needed to compare other methods of echocardiographic measurement of RV function ${ }^{(9)}$.

\section{MWT in functional assessment of patients with pulmonary hypertension:}

Regarding 6MWT in our study we did 6MWT only for adult patients this was justified by that there is no reference values for the 6MWT in healthy children In most studies, In our study, the mean 6MWT of our adult patients on presentation was 312.93 meters \pm 81.92 range (120-430).

In our study, the mean 6MWT was 218.75 meters \pm 65.58 (range 120-340) in adult patients with Eisenmenger syndrome

This was lower than a study conducted by Güngör et al. who reported that mean 6MWD was 347 meters in patients with Eisenmenger syndrome ${ }^{(\mathbf{1 0})}$. 
This was lower also form the mean 6MWT from REHAB registry which was 370.0 meters $(280.0-451.5)^{(6)}$.

The difference between our study and these studies in the mean 6MWT which is in our study is lower than the other studied could be explained easily that in all three registries the patients with Eisenmenger syndrome received P.HTN specific therapy in contrast to our patients who were receiving general measures and PDE I.

\section{Medical treatment:}

In pediatric group:41.9\% received ACEI, 4.8\% received lanoxin, 48.6\% received PDE.I, and $2.9 \%$ received ERA, In adult group:35.6\% received ACEI, 8.9\% received lanoxin, $48.9 \%$ received PDE.I, and $6.8 \%$ received ERA.

This was significantly different from all other registries

In REVEAL registry ${ }^{(\mathbf{8})}, 49 \%$ received PDE.I, and $47 \%$ received ERA, 46\% were on dual combination PAH specific therapy (PDE.I+ ERA) and 9\% were on triple combination (PDE.I+ ERA+ prostanoids)

None of their patients were on ACEI nor Digoxin

It was different also from the TOPP registry ${ }^{(5)}$.in which:

Patients from 3 months till 2 years, $8 \%$ received lanoxin, $46 \%$ received PDE.I, and $16 \%$ received ERA

Patients from 2-6 years, 7\% received lanoxin, 46\% received PDE.I, and 39\% received ERA

In REVEAL-Children registry, 45\% received PDE.I, 28\% received Prostacyclin analogues and $47 \%$ received ERA, 24\% were on dual combination PAH specific therapy (PDE.I+ ERA) and 5\% were on triple combination (PDE.I+ ERA+ prostanoids $^{(11)}$
In the REHAP registry, $19 \%$ received PDE.I, 11\% received Prostacyclin analogues and $60 \%$ received ERA, $9.5 \%$ were on dual combination PAH specific therapy (PDE.I+ ERA) ${ }^{(6)}$

This significance difference between our registry and other registries could be justified by the high cost of the PHTN target drugs and its unavailability in our country

\section{Conclusion:}

Our descriptive study confirmed many characteristic similarities between our patients, middle-east data, and the international data.

Limitations: Relatively small number of patients and it was a single center study

\section{REFERENCES:}

1. Sliwa K, Carrington MJ, Becker A, et al. Contribution of the human immunodeficiency virus/acquired immunodeficiency syndrome epidemic to de novo presentations of heart disease in the Heart of Soweto Study cohort. Eur Heart J 2012;33: 866-74.

2. Silvestry F. Pulmonary artery catheterizetion: interpretation of hemodynamic values and waveforms in adults. Uptodate. (2015) Retrieved on April, 17, 2017

3. Berger RM, Beghetti M, Humpl T, et al. Clinical features of paediatric pulmonary hypertension: a registry study. Lancet 2012; 379: 537-546.

4. van Loon RL, Roofthooft MT, Hillege HL, et al. Pediatric pulmonary hypertension in the Netherlands: epidemiology and characterization during the period 1991 to 2005. Circulation. 2011; 124 (16): 1755-64.

5. Berger RM, Beghetti M, Humpl T, et al. Clinical features of paediatric pulmonary hypertension: a registry study. Lancet. 2012; 379 (9815): 537-46. 
6. Alonso-Gonzalez R, Lopez-Guarch CJ, Subirana-Domenech MT, et al. Pulmonary hypertension and congenital heart disease: An insight from the REHAP National Registry. International Journal of Cardiology. 2015; 184:717-23.

7. Thienemann F, Dzudie A, Mocumbi AO, et al. Rationale and design of the Pan African Pulmonary hypertension Cohort (PAPUCO) study: implementing a contemporary registry on pulmonary hypertension in Africa BMJ Open 2014;4:e005950.

8. Badesch DB, Raskob GE, Elliott CG, et al. Pulmonary arterial hypertension: baseline characteristics from the REVEAL Registry. Chest. 2010; 137(2):376-87.
9. Lee JZ, Low SW, Pasha AK, et al. Comparison of tricuspid annular plane systolic excursion with fractional area change for the evaluation of right ventricular systolic function: a metaanalysis. Open Heart 2018; 5:e00667.

10. Gungor H, Ertugay S, Ayik MF, et al. Clinical and hemodynamic features of Eisenmenger syndrome patients at the time of first admission: a tertiary referral-center experience. Anatol J Cardiol. 2012; 2:11-5.

11. Barst RJ, McGoon MD, Elliott CG, et al. Survival in childhood pulmonary arterial hypertension: insights from the registry to evaluate early and long-term pulmonary arterial hypertension disease management, Circulation. 2012; 125 (1):113-22. 
تسجيل مرضى ارتفاع ضغط الام بالثريان الرئوي المتقدمين إلى مستثفيات جامعة عين شمس

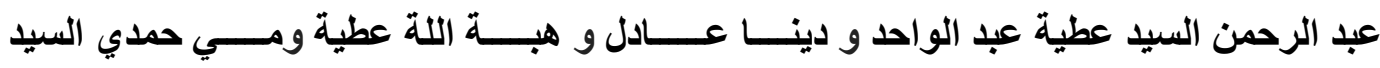
قسم القلب ـ كلية الطب - جامعة عين شمس

الخلفية: كان لسجلات المرضى الذين بعانون من ارتفاع ضغط الثرياني الرئوي دورًا أساسيًا في تحديد اعراض

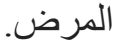
الهلف: توفير بروتوكول لتقييم المرضى الذين يعانون من ارتفاع ضغط الثريان الرئوي بما في ذلك الفحص و التقييم

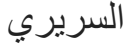

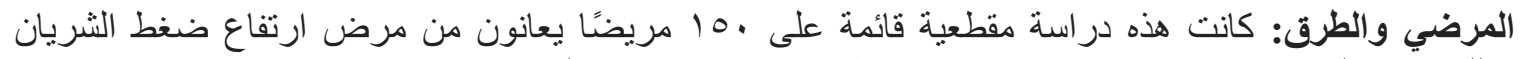

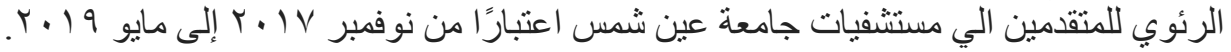

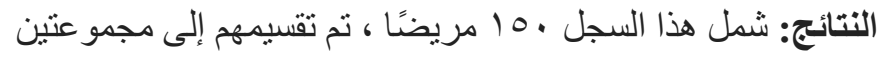

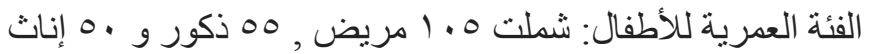

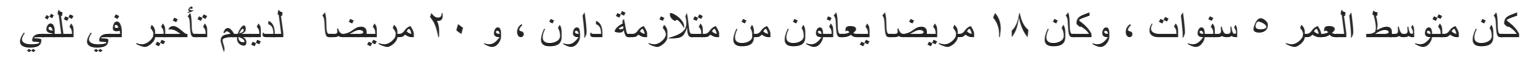
العلاج

وكان المسببات الأكثر شيوعا هو الثقب بين البطينين تليها أمر اض القلب الخلقية المعقدة

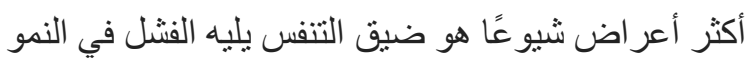

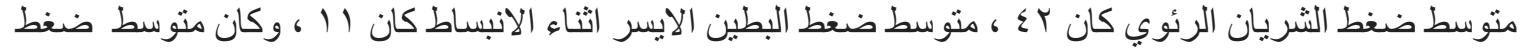
الاذين الايمن 8.79.

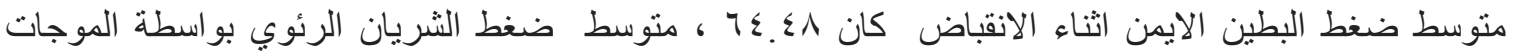

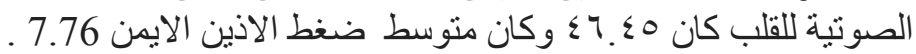

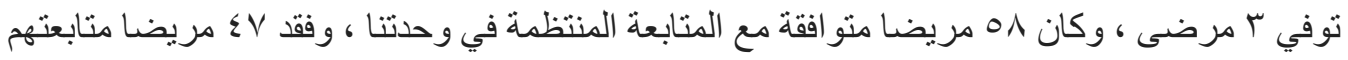

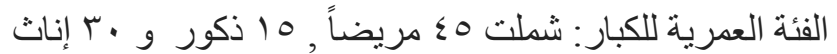

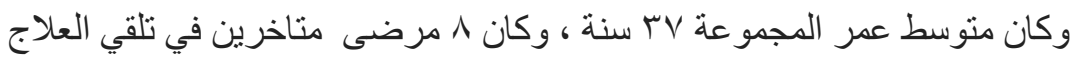

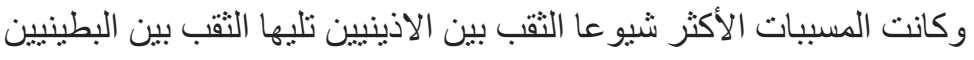

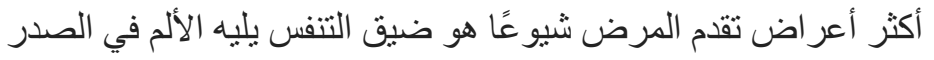

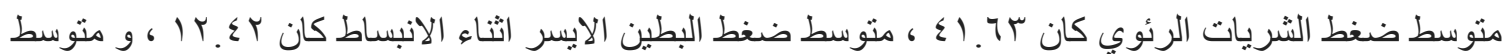

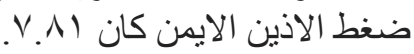

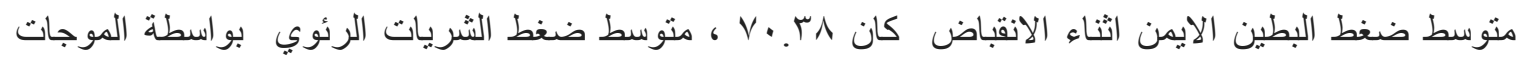

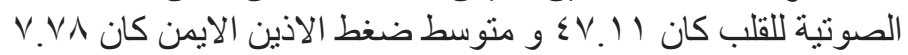

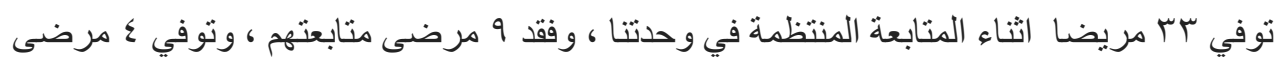

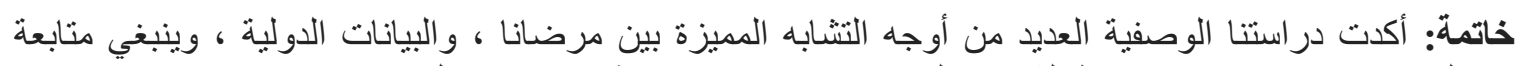

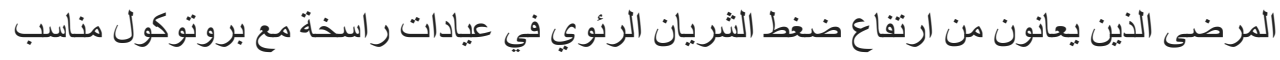

